\title{
O papel das escolas no combate às masculinidades tóxicas
}

Susana de Castro ${ }^{1}$

Resumo: o artigo aborda os efeitos nocivos do machismo sobre os homens. As identidades fixas, femininas ou masculinas, limitam a liberdade de ser e sentir de homens e mulheres. Aborda também a atração que o trabalho com o tráfico de drogas exerce sobre os jovens dos países emergentes. O fim do humanismo na era do capitalismo neoliberal leva o jovem da periferia dos grandes centros urbanos dos países emergentes a buscar o necroempoderamento. A mudança da cultura machista deve começar nas escolas, com o questionamento pedagógico das bases pretensamente biológicas da ideologia patriarcal.

Palavras-chaves: machismo; sexismo; patriarcado; capitalismo neoliberal.

\section{The role of schools in combating toxic masculinities}

\begin{abstract}
This article addresses the harmful effects of machismo on men. The fixed identities, feminine or masculine, limit the freedom of being and feeling of men and women. The paper also addresses the attraction that working with drug trafficking has to young people in developing countries. The end of humanism in the era of neoliberal capitalism leads the youth from the periphery of the great urban centers to seek necro-empowerment with the drug traffic. The change of macho culture must begin in schools, with the pedagogical questioning of the supposedly biological bases of the patriarchal ideology.
\end{abstract}

Keywords: machismo; sexism; patriarchy; neoliberal capitalism.

${ }^{1}$ Doutora em filosofia e professora associada do departamento de filosofia da UFRJ. E-mail: susanadec@gmail.com 
“O machismo favorece sempre aos homens?”, pergunta a socióloga Helieth Saffioti (2004, p. 35). Normalmente responderíamos que sim, pois afinal o machismo é justamente a expressão que representa exercício do poder arbitrário dos homens sobre as mulheres. Mas, apesar de serem de fato as grandes prejudicadas, pois impedidas de desenvolver o uso da razão e exercitar o poder plenamente, o machismo também causa uma série de prejuízos aos homens.

O pensamento conservador machista atribui às identidades masculinas e femininas características físicas e psicológicas permanentes. Assim como a mulher seria naturalmente gentil, dócil e passiva, o homem seria naturalmente corajoso, agressivo e arrojado. Quem apresentar uma ou outra característica tipificada como sendo do outro, e não do seu sexo biológico, logo será alvo de crítica. Esta acontece tanto na forma da censura direta, quando o pai ou a mãe, por exemplo, criticam determinado linguajar, traje, ou comportamento do/a filho/a, por ser típico do sexo oposto ao do filho/filha, quanto na forma indireta, através de olhares hostis ou risos de zombaria e escárnio. Direta, ou indiretamente, o fato é que em ambos os casos aquele ou aquela que é alvo da censura e zombaria sofre.

Todo mundo quer ser aceito, reconhecido e amado, pois somos seres gregários, como dizia Aristóteles. Poucos ousam driblar as normas de expressão de gênero atribuídas a seu sexo biológico, temendo a rejeição. O medo do estigma e da censura, assim como o medo de perderem o status de 'sexo superior', acaba impedindo muitos homens, jovens e adultos, de serem emotivos, sensíveis, delicados, empáticos ${ }^{2}$.

A educação em uma sociedade verdadeiramente democrática, comprometida com a diminuição das desigualdades, possui a enorme tarefa não só de desestabilizar os paradigmas de identidades femininas subalternizadas ideologicamente pelo machismo, mas também os modelos de identidades masculinas tóxicas, frutos do mesmo machismo.

Por que afinal uma pessoa não pode ser tanto 'dócil', quanto 'agressiva'? Por que quando um grupo composto por homens e mulheres é confrontado com a necessidade de execução de uma tarefa perigosa é sempre um homem escolhido para executá-la? Por que é feita a associação entre expressão de gênero e desejo sexual, de tal forma que uma pessoa que possui uma expressão de gênero, isto é, comportamento, atitudes, vestimenta, 'próprias' ao sexo oposto ao seu, é automaticamente considerada homossexual? Por que um homem necessariamente precisa ser o provedor da família? Por que o homem sente sua virilidade posta em xeque quando não consegue cumprir seu papel de provedor da família?

A ideologia patriarcal nos leva a crer que há uma norma universal que determina o feminino e o masculino como categorias excludentes, isto é, grosso modo, que meninos gostam de carro e são agressivos, enquanto meninas gostam de bonecas e são dóceis. Quem não reproduz a norma de performance de gênero própria a seu sexo é visto como um anormal. Assim, na escola, meninas que gostam de brincar

\footnotetext{
${ }^{2}$ Cf. o documentário norteamericano da netflix The Mask you live in, no qual são retratados os traumas que a educação que
} estimula a hipermasculinidade provoca nas pessoas. 
de carrinho e andar de calça comprida, e meninos que gostam de brincar de bonecas e deixar o cabelo crescer são repreendidos pelos coleguinhas e pela professora, "isso é coisa de menino" ou "isso é coisa de menina".

O modelo de feminilidade dócil percorre os séculos e persiste até hoje, ainda que abalado fortemente pelo movimento feminista. A visão tradicional diz que 'masculino' e 'feminino' são opostos que se complementam. Mas o que constatamos é que, por um lado, as mulheres são as maiores vítimas de violência doméstica e de assédio no trabalho, e, por outro, os homens são as maiores vítimas de acidente de carro e assassinato no país. Muitas mulheres são vítimas de violência, perpetrada por seus maridos e namorados, ou de assédio, por seus chefes e colegas de trabalho, o que demonstra que 'masculino' e ‘feminino' não são opostos que se ‘complementam', mas sim desiguais: a posição masculina detém mais status e poder do que a feminina, por isso quem assedia são os homens, que se acham no direito 'natural' de interpelar uma aluna, uma secretária, uma estagiaria a fim de obter favores sexuais. Mas, por outro lado, os homens são vítimas também desse modelo de masculinidade caracterizado por sua oposição ao feminino. A perfomance de gênero da masculinidade hegemônica nos países latinoamericanos possui entre seus postulados principais, independência financeira e poder de compra, desprezo pelas atividades e 'virtudes' femininas, indiferença ao perigo e afirmação da autoridade em todos os níveis - onde estiver, no bar, em casa, na rua, sua presença e voz deve se sobrepor a de todos os demais.

Precisamos urgentemente problematizar os pressupostos que corroboram a tese de que haveria uma expressão de gênero fixa para cada sexo e que essa expressão de gênero reflete uma 'subjetividade', uma identidade, também fixa, ou masculina, ou feminina. Presentes desde cedo na criação e educação de crianças e jovens, esses pressupostos hoje, mais do que nunca, geram mais violência e desordem. Precisamos falar sobre formas de combater modelos de masculinidades tóxicas, pois estas não são só prejudiciais às mulheres, elas prejudicam os próprios homens.

\section{Narcocapitalismo global e necroempoderamento}

A crise de emprego provocada pela adesão cega a um modelo econômico neoliberal descompromissado completamente com qualquer princípio humanista (MBEMBE, 2017) provoca a exacerbação de masculinidades tóxicas. Atraídos pelo poder proporcionado pelo dinheiro, jovens das periferias urbanas dos chamados países emergentes, como o Brasil, optam, na ausência de qualquer indicação do poder público e privado de que possam ser absorvidos por um mercado de trabalho que lhes dê alguma perspectiva de ascensão social, pelo necroempoderamento (VALENCIA, s/d; VALENCIA, 2010), isto é, pela inserção rápida e extremamente lucrativa em um mercado de trabalho bem peculiar, o narcotráfico. O tráfico de drogas figura como o negócio mais lucrativo do mundo, seguido do comércio legal dos hidrocarbonetos e do turismo (VALENCIA, 2010, p.20). 
O capitalismo dos países periféricos não abala a divisão internacional do trabalho entre países exportadores de produtos industrializados e tecnologia, e países exportadores de matéria prima e fornecedores de mão de obra barata para empresas estrangeiras no país. Ex-colônias europeias, os países latino-americanos continuam dependentes de alguma matriz, modelo de civilização e de desenvolvimento. Mas vivemos no século XXI uma situação inusitada. Até então, apenas tentávamos seguir os passos dos países industrializados, hoje, somos também os maiores produtores de drogas do mundo. Exportamos para os mercados consumidores da Europa e dos EUA. O fluxo do mercado mundial das drogas representa a distopia do capitalismo globalizado.

$\mathrm{Na}$ base desse grande comércio global está toda uma cultura voltada para o culto a masculinidades tóxicas, hegemônicas:

entendemos como performance de género masculino a la obediencia acrítica de lós varones al desempeñar (performar) las normas de género dictadas por la masculinidad hegemónica, la cual tiene entre sus postulados más arraigados: la respetabilidad económica, 'la indiferencia ante el peligro, el menosprecio de las virtudes femeninas y la afirmación de la autoridad en cualquier nivel(Monsiváis 1981, 9). (VALENCIA, s/d; itálicos meus)

A autoridade é uma característica fundamental para a identidade masculina hegemônica. Essa autoridade aqui é ampla, é tanto a autoridade baseada na superioridade masculina, quanto a autoridade baseada no domínio da força. Tanto no Brasil, quanto nos outros países da América Latina e Central, o poder dos narcotraficantes de outorgar a morte aos outros é considerado o valor mais alto de reconhecimento. Quem chega a esse patamar alcança o necroempoderamento, ou seja, visibilidade e poder dentro da comunidade em que vive.

Como mostram as letras dos funks das favelas cariocas, os jovens entram no tráfico em busca de poder e dinheiro, e, ao mesmo tempo, atraídos pela afirmação de suas identidades masculinas, que de outra forma, a pobreza, o desemprego e o racismo abalaria. ${ }^{3}$ Querem ser consumidores das grandes marcas, as marcas caras que a sociedade do hiperconsumo propagandeia como objetos de luxo. Querem atrair mulheres e fama. Então, para alcançar esse alto patamar de consumo, abrem mão do ideal burguês de estudo e trabalho para ser tornarem assassinos violentos e cruéis.

\footnotetext{
3 A letra da música do Mc Orelha, "Na faixa de gaza", espelha claramente o significado dessa atração dos jovens das favelas cariocas pelo necroempoderamento: "só homem bomba, //Na guerra é tudo ou nada,// Várias titânio no pente, //Colete a prova de bala, //Nós desce pra pista pra fazer o assalto, //Mais ta fechadão no doze, //Se eu to de rolé 600 bolado, //Perfume importado pistola no couto, //Mulher ouro e poder, //Lutando que se conquista, //Nós não precisa de credito, //Nós paga tudo a vista, //É ecko, lacoste, é peça da oakley, //Várias camisas de time, //Quem ta de fora até pensa que é mole viver do crime, //Nós planta humildade, pra colher poder, //A recompensa vem logo após, //Não somos fora da lei, //Porque a lei quem faz é nós, //Nós é o certo pelo certo, //Não aceita covardia, //Não é qualquer um que chega e ganha moral de cria, //Consideração se tem, //Pra quem age na pureza, //Pra quem ta amando o papo é reto //Bota as peça na mesa, //Quantos amigos eu vi, Ir morar com deus no céu, //Sem tempo de se despedir, / / Mais fazendo o seu papel, / / Por isso eu vô manda, / / Por isso eu vô manda assim, //Comando vermelho rl até o fim, //É vermelhão desde pequenininho, //Só menor bolado nas favela do baixinho// Não dá, não dá, não dá não //Por isso eu mando assim, //Comando vermelho rl até o fim, É vermelhão desde pequenininho,// Só menor bolado nas favela do baixinho// Nóis ta que ta heim, caralho! (..)". [itálicos meus].
} 
O capitalismo globalizado neoliberal silencia-se sobre essa outra globalização, a das drogas, mas, na verdade, a sociedade do hiperconsumo é também a do fim do humanismo, pois empurra para o crime, jovens prontos a matar e a morrer por um rolex ou por uma blusa lacoste, enquanto no outro hemisfério, o grande comerciante de armas e drogas não participa diretamente das mortes violentas, desencadeadas pelo necroempoderamento dos jovens da periferia do capitalismo, apenas de seus lucros exorbitantes.

Os jovens não trabalhariam no tráfico de drogas se não estivessem tão apegados às identidades masculinas hegemônicas e se o sistema capitalista global e a divisão internacional do trabalho não os excluíssem do mercado de trabalho formal.

Como mostra Sayak Valencia (2010), o narcotráfico é a face invisível do neoliberalismo. O negócio ilegal de tráfico mundial de drogas movimenta muito dinheiro em todo o mundo e atrai para suas fileiras jovens de países periféricos que não possuem espaço de ascensão social dentro do mercado ordinário de trabalho. Não há simplesmente emprego para todo mundo dentro desse modelo rentista, tecnológico e globalizado do capitalismo.

O capitalismo neoliberal ao mesmo tempo em que estimula o hiperconsumo, exclui grande parte da população, os desempregados ou os mal-remunerados, do paraíso do consumo. O desemprego em massa cria um problema grave para as identidades masculinas.

Precisamos discutir nas escolas desde cedo as expressões de gênero monolíticas e suas consequências nocivas para homens e mulheres, para que os jovens saibam que não há a necessidade de serem traficantes de drogas e andarem armados e com dinheiro nos bolsos para serem reconhecidos e amados. Por outro lado, é evidente que as mulheres ao serem socializadas dentro da ordem patriarcal de gênero acabam apoiando essa ideologia sexista de que o homem para ser amado deve ter dinheiro e poder. Há um enorme número de mulheres machistas, justamente porque, criadas dentro da ideologia patriarcal, são incapazes de questionar sua inferioridade social, achando-a 'normal' e 'natural'.

Necessitamos urgentemente de uma educação emancipatória que liberte desde cedo as crianças da opressão da norma de expressão de gênero e de sexualidade. É preciso distinguir claramente diferença e desigualdade (SAFFIOTI, 2010, p.37). Não há nada no fato da diferença sexual que justifique uma desigualdade social. A desigualdade social entre homens e mulheres é fruto de uma ideologia machista patriarcal que precisa ser fortemente combatida.

\section{A autoridade masculina 'natural', o patriarcado moderno}

O sexismo é uma ferramenta ideológica utilizada para justificar a distribuição desigual de poder entre homens e mulheres. Trata-se de uma 'ideologia' visto que penetra na imaginação e pensamento da população invertendo os fenômenos. Assim, por exemplo, é comum no Brasil o homem dizer que 'comeu' fulana, quando, na verdade, se fosse o caso de alguém “comer” alguém, essa pessoa seria a mulher e não o homem, já que é justamente a conformação da vulva e da vagina como uma 'boca' que lhes 
permitiria 'comer'. O mito da "vagina dentada" expressa justamente o medo dos homens de serem castrados pela vagina no ato sexual (SAFFIOTI, 2004, p.33).

Historicamente, os homens invejavam as mulheres por estas serem capazes de "engendrar nova vida, de produzir todos os nutrientes necessários ao desenvolvimento dos fetos e, ainda, de fabricar internamente leite para alimentar os bebês" (SAFFIOTI, 2004, p.33). Procuram provar sua "superioridade" com feitos e ações (inclusive, feitos sexuais). Escamoteiam o complexo de inferioridade com a exaltação narcísica do próprio mérito. Esbanjam virilidade e desprezam a feminilidade, considerando as mulheres seus inferiores na escala humana, pois menos inteligentes (sic) e mais fracas, por natureza. Capazes de resistir às dores do parto, as mulheres apresentam, além disso, capacidade de suportar sofrimentos de ordem psicológica de modo invejável (SAFIOTTI, 2004, p.33). A transformação da desvantagem masculina em vantagem ilustra muito bem esse modo de 'inversão' mediante o qual as ideologias operam.

A divisão sexual do trabalho representa o principal fundamento do patriarcado, permeia a estrutura tanto da família quanto das organizações privadas e civis (escola, igreja, escritórios, estabelecimentos comerciais etc.) e das instituições públicas (congresso, tribunais, delegacias, quartéis etc.). É, portanto, equivocado crer que o patriarcado, o direito político masculino sobre as mulheres, seja uma questão exclusivamente familiar, ou seja, de foro privado, ou que ele teria acabado quando, no Brasil, a Constituição de 1988 reconheceu a cidadania ampla, a homens e mulheres.

A ideologia patriarcal, a suposta inferioridade natural das mulheres, justifica o direito político, de autoridade, dos homens sobre as mulheres, e dá suporte à divisão sexual do trabalho. Assim, atividades como costura, enfermagem, faxina seriam tipicamente femininas, pois mais ou menos replicam na esfera pública as tarefas das mulheres em casa, e atividades como mecânica, gerência, construção civil seriam masculinas. Essa naturalização da divisão do trabalho calcada na inferioridade da mulher seria, na verdade, uma inversão ideológica do princípio da igualdade entre os sexos, nas sociedades pré-patriarcais (SAFFIOTI, 2004, p.60).

Como mostra Carole Pateman (1988), a sociedade civil, criada em torno da noção de igualdade e liberdade contratual, baseia-se, na verdade, na igualdade e liberdade masculina e na subordinação feminina. Os homens são igualmente livres e iguais porque possuem uma esposa subordinada a eles. A identidade masculina é construída, a partir dessa noção de fraternidade de machos provedores e fêmeas submissas. O homem é o único responsável pelo sustento da família. A mulher deve se preocupar exclusivamente com o bem-estar do marido. Do século XVII, quando essa ideologia da identidade

\footnotetext{
4 Para a escritora norte americana Valerie Solanas, o homem na verdade gostaria de ser mulher ("women, in other words, don't have penis envy; men have pussy envy"), mas como não pode, compensa essa frustração fazendo do mundo um monte de merda (a shitpile); SOLANAS, 1996, p. 161. De uma forma menos direta, mas nem por isso menos pessimista, a filósofa britânica, Carole Pateman acredita que a derrota da mulher se deu quando o homem descobriu seu papel crucial na fecundação (apud Bachhofen) e substituiu o matriarcado pela criação da civilização. O patriarcado moderno fará 'nascer' através do poder criador masculino a várias instituições, inclusive a o próprio Estado moderno (1988, p.35).
} 
masculina e feminina atrelada à divisão sexual de trabalho surgiu, para cá, muita coisa mudou, é certo, mas essa noção básica de masculinidade como ligada à capacidade de sustentar uma família, de ser o 'provedor', não mudou. Tanto é assim que o desemprego é uma situação muito mais dolorosa para um homem do que para uma mulher. Desempregado por muito tempo, o homem pode tanto enveredar para alcoolismo, quanto para a violência doméstica, 'descontando' sua frustração na esposa e filhos. Isso ocorre porque ele não é 'livre' para adotar outras formas de masculinidade. A sua formação social, familiar e escolar, lhe incutiu a ideia de que sua masculinidade é construída em oposição à feminilidade, ou seja, o homem é o oposto da mulher, por isso não pode fazer nada que seja considerado tarefa tipicamente feminina sem pôr em risco sua identidade masculina. Lembremos que as identidades são socialmente e historicamente construídas. No momento do surgimento da sociedade capitalista, no século XVII, era interessante ao patriarcado acabar com a ideia de que um casal pudesse ser uma unidade de produção cooperativa, que o lar pudesse ser um ambiente tanto de reprodução sexual quanto de produção econômica. Antes, nas sociedades pré-modernas e pré-capitalistas da Europa, os ambientes domésticos eram também lugares de produção, e as mulheres participavam em igual medida que os homens do trabalho (PATEMAN\& BRENNAN, 1976). Isso deixou de ser desejável a partir do momento em que o capitalista deteve em suas mãos os meios de produção, restando ao trabalhador apenas a sua força de trabalho.

Hoje, o trabalho passa por uma total reformulação. As fábricas automatizadas dispensam mão de obra operária, atividades meio e atividades fim são terceirizadas, direitos trabalhistas são retirados. Nesse contexto, o tráfico de drogas passa a ser uma opção de 'trabalho' para muitos jovens. Desempoderados pela ausência de poder aquisitivo, os jovens são atraídos pelo necroempoderamento (VALENCIA, 2010) através do tráfego de drogas. Nem todo jovem morto em confronto entre polícia e traficante pertencia de fato ao tráfico, mas o que os que participam do negócio das drogas sabem que podem morrer a qualquer momento. Os mortos figuram nessa conta dos corpos matáveis do capitalismo liberal, aqueles que pertencem as 'minorias' pobres e marginalizadas das sociedades capitalistas. ${ }^{5}$

\section{Conclusão}

Ao contrário do que afirmam seus defensores, esse modelo de masculinidade e feminilidade antagônicas foi histórica e socialmente construído. Ele serve ao sistema capitalista patriarcal que funda a igualdade civil na subordinação das mulheres (PATEMAN, 1988). Se a cultura e sociedade é machista, a

\footnotetext{
${ }^{5}$ Hoje, não é preciso mais uma guerra 'oficial' para exterminar os corpos 'indesejáveis', a guerra às drogas cumpre esse papel nos chamados países periféricos. O número de mortos pela guerra às drogas nos grandes centros urbanos equivale ao número de mortos em uma guerra civil. No caso específico do Rio de Janeiro, as favelas cariocas são territórios de 'estado de exceção', nelas não vigoram as mesmas leis que no chamado 'asfalto', a polícia pode entrar atirando e matando, pois está legitimada pela excepcionalidade da 'guerra' às drogas que lhe garante a impunidade através da tese da 'legítima defesa' (ver ZACCONE, 2016).
} 
única forma de desconstruir masculinidades que fazem vítimas entre as mulheres e os homens igualmente, é começando pela base, pela educação infantil. Se desde pequena a criança aprende que há dentro dela princípios masculinos e femininos (animus e anima -JUNG apudSAFFIOTI, p. 16, 2004), passa a respeitar melhor o 'outro' e não querer se impor ou se submeter. A escola possui um papel enorme a cumprir, desnaturalizando a divisão sexual do trabalho e as expectativas em torno do que é tipicamente feminino ou tipicamente masculino.

\section{Referências}

MBEMBE, Achille. "A era do humanismo está terminando". In: www.ihu.unisinos.br. Acesso em 10/11/2018.

PATEMAN, Carole. The Sexual Contract. Stanford, California: Stanford University Press, 1988. .; BRENNAN, Teresa. "Mere auxiliaries to the commonwealth': Women and the origins of liberalism". In: Political Studies, vol. XXVII, No. 2, 1976, pp. 183-200.

SAFFIOTI, Heleieth I.B. Gênero, patriarcado, violência. São Paulo: Perseu Abramo, 2004.

SOLANAS, Valerie. The Scum Manifesto. In: Harron, Mary \& Minahan, Daniel. I Shot Andy Warbol. Londres: Bloomsbury, 1996.

VALENCIA, Sayak. Capitalismo Gore. Santa Cruz de Tenerife: Melusina, 2010. "Capitalismo gore, narcomáquina y performance de género". In: Emisférica, s/d. www.emisferica.org. Acesso em 22/11/19.

ZACCONE, Orlando. Indignos de Vida. Rio de Janeiro: Revan, 2016. 